\title{
LAS SINGULARIDADES DEL DELITO DE ACOSO MORAL EN EL ÁMBITO DEL TRABAJO (MOBBING): ARTÍCULO 173.1, PÁRRAFO 2º , DEL CÓdIGO PENAL
}

THE SINGULARITIES OF MORAL HARASSMENT AT THE WORKPLACE (MOBBING): ARTICLE 173.1, PARAGRAPH 2º, OF THE CURRENT PENAL CODE

\author{
Antonio MARTÍNEZ CANO ${ }^{1}$
}

Ilustre Colegio Provincial de Abogados de Jaén, España

Recibido: 24 Mayo 2021 / Aceptado: 25 Julio 2021

\section{Resumen}

El acoso laboral es uno de los principales problemas que en la actualidad padece la población trabajadora en nuestro país. El presente estudio da a conocer la limitada protección que, ante este tipo de conductas, brinda el tipo penal que lo regula, referido con carácter exclusivo a los ataques cometidos hacia la integridad moral de las personas trabajadoras, además de otros muchos elementos de tipicidad que circunscriben notablemente su ámbito de aplicación. Sin lugar a dudas, es uno de los delitos que, por las exigencias que entraña el principio de tipicidad penal, su regulación difiere notablemente respecto a la prevista en otros ámbitos del ordenamiento jurídico.

Palabras clave: Delito, Acoso laboral, Tipicidad penal, Integridad moral

\begin{abstract}
Workplace harassment is one of the main problems that the working population of our country currently suffers from. The present study reveals the limited protection that, in the face of this type of conduct, the criminal type that regulates it provides, referring exclusively to attacks committed against the moral integrity of workers, in addition to many other typical elements that notably circumscribe its scope of application. For sure, it is one of the crimes that, due to the requirements that the principle of criminality entails, its regulation differs notably in terms of the provided by other areas of the legal system.
\end{abstract}

Keywords: Crime, Workplace harassment, Criminal offense, Moral integrity 
SUMARIO: I. Introducción. II. El acoso laboral desde una perspectiva multidisciplinar. III. Ubicación del delito de acoso moral laboral (mobbing) en el código penal. IV. Elementos del tipo penal de acoso moral laboral (mobbing). Interpretación jurisprudencial. V. Conclusiones. VI. Bibliografía.

SUMMARY: I. Introduction. II. Workplace harassment from a multidisciplinary perspective. III. Location of the offense of moral harassment (mobbing) in the penal code. IV. Elements of the criminal type of workplace moral harassment (mobbing). Jurisprudential interpretation. V. Conclusions. Vi. Bibliography.

\section{INTRODUCCIÓN}

Las situaciones de acoso surgidas en el ámbito del trabajo, también conocidas por el anglicismo mobbing, constituyen una realidad social que ha existido de manera permanente en nuestra civilización desde que, en su día, se implantaron las relaciones de carácter laboral en el ámbito privado y funcionarial. Tales conductas humanas, entendidas como actos o comportamientos de fiel persecución que una persona ejerce sobre otra en el ámbito del trabajo, causándole un verdadero estado de hostigamiento, en una imperante mayoría de las ocasiones no son merecedoras de recibir una respuesta por parte del ius puniendi de nuestro Estado en aplicación de nuestro Derecho penal. La razón habitual de esta destacada impunidad criminal no reside en la baja entidad o gravedad con la que tales actos son normalmente cometidos, sino que, por el contrario, se debe a la limitada, y muy particularizada, previsión que el tipo penal de acoso moral en el ámbito del trabajo recibe en nuestro Código Penal. ${ }^{2}$

En puridad, el tipo penal del mobbing no abarca la totalidad de conductas acosadoras susceptibles de ser cometidas en las relaciones de trabajo; sino que, la protección jurídico-penal de nuestro ordenamiento jurídico, ante la comisión de unos hechos que sean merecedores de ser calificados como acoso surgido en las relaciones de trabajo, se circunscribe, en atención al concreto bien jurídico protegido que se lesione, a los siguientes tipos penales: el delito de stalking, o también conocido como delito de acoso ilegítimo genérico, ${ }^{3}$ que protege el bien jurídico de la libertad de obrar de las personas; el delito de acoso moral en el ámbito del trabajo, o mobbing, que protege el bien jurídico de la integridad moral de la persona trabajadora, el cual constituye el verdadero objeto del presente estudio; y, por último, el delito de acoso sexual en el ámbito del trabajo, ${ }^{4}$ protector de la libertad e indemnidad sexuales de la persona trabajadora. 
De la delimitación jurídico-penal que reciben este tipo de conductas en nuestro ordenamiento jurídico penal puede apreciarse, de manera indubitada, que una conducta acosadora surgida en el ámbito del trabajo puede recibir hasta una triple protección por parte de nuestro Derecho penal, y no exclusivamente una. Por este concreto motivo, para ser aplicado específicamente el tipo penal del mobbing, resulta imprescindible que la conducta penalmente reprochable sea idónea para ocasionar la lesión del bien jurídico "integridad moral", y no otro. Esta particularidad dará lugar a que el tipo penal del mobbing no pueda ser considerado o calificado como un delito genérico de acoso en el trabajo, como si su ámbito de aplicación abarcarse la totalidad de conductas de acoso surgidas en el ámbito laboral; sino que el tipo penal del mobbing, en realidad, se orienta a un acoso, únicamente moral, en el ámbito del trabajo. Este aspecto, per se, limitará en gran medida su ámbito de aplicación.

Pero es que, en suma de la particularidad advertida, el tipo penal del mobbing, o acoso moral en el ámbito del trabajo, exige de tan extraordinarios y específicos elementos de tipicidad para ser apreciado que, como argumentaremos a lo largo de nuestro trabajo, acotan de forma notable su aplicación. Por eso mismo, si como lector es la primera vez que entras en contacto con la regulación de este tipo delictivo, debes de tener presente que una multitud de situaciones que entenderás como ineludiblemente merecedoras de recibir un castigo penal por medio de este delito, finalmente no lo serán. Para nuestro ordenamiento jurídico penal no toda conducta de aniquilamiento, hostigamiento o desgaste mental llevada a cabo por parte de una persona hacia otra, las cuales se encuentran unidas por una relación de trabajo, es merecedora de reproche penal en aplicación del delito de acoso moral laboral o mobbing; al contrario de lo que sucede en otros ámbitos del ordenamiento jurídico.

Sin querer entrar en un análisis más profundo, que con obviedad se extralimitaría del fin perseguido en este apartado, a continuación se desarrolla nuestro estudio del delito de mobbing; el cual no deja de ser una manifestación más de los rigurosos efectos que comporta el principio de tipicidad penal dentro de esta rama del Derecho y, en consecuencia, de cómo aquellos comportamientos que pueden ser calificados de acoso, y por tanto sancionables, desde la perspectiva de otros ámbitos del ordenamiento jurídico, podrán no serlo desde la óptica de nuestro Derecho penal. 


\section{EL ACOSO LABORAL DESDE UNA PERSPECTIVA MULTIDISCIPLINAR}

En la actualidad, tras multitud de estudios psicosociales, se ha concluido que el acoso o mobbing es uno de los problemas que, con más frecuencia, padecen las personas en su puesto de trabajo. Como referencia, podemos tomar el estudio realizado por la Asociación contra el Acoso Psicológico y Moral en el Trabajo, uno de los más reconocidos en la materia, con datos de 2017, el cual concluye que en España un 15\% de los trabajadores sufre acoso o mobbing en su entorno laboral; dato que, traducido en cifras, supone que más de 3 millones del conjunto total de trabajadores españoles quedan afectados por este tipo de conductas en su trabajo. ${ }^{5}$

Comenzamos hablando del acoso en las relaciones de trabajo como fenómeno o problema social, y no concretamente del tipo penal que lo regula, que es el verdadero objeto de nuestro estudio, no porque este autor tenga la intención de hacer una disertación multidisciplinar de su figura, sino porque, como hemos adelantado con anterioridad, este problema de ámbito laboral es una realidad social que puede ser acometida, ya no sólo desde una pluralidad de ramas científicas (psicología, sociología, etcétera), sino también desde distintos ámbitos del ordenamiento jurídico, así como sus correspondientes órdenes jurisdiccionales. Siendo cierto que su origen tiene que producirse de forma necesaria en el ámbito del trabajo, pudiendo entenderse de este modo que nos estamos refiriendo a un problema de ámbito laboral, hemos de advertir que nada queda más lejos de la realidad. Las situaciones de acoso en el trabajo pueden ser acometidas, principalmente, desde el ámbito de cuatro órdenes jurisdiccionales: social, contencioso-administrativo, penal y constitucional. A continuación, nos referiremos de manera breve a cada uno de ellos.

En sus orígenes, el concepto de acoso laboral surgió en la psicología para abordar, desde un punto de vista terapéutico, situaciones o conductas muy diversas de estrés laboral que tenían en común la reiteración en el tiempo, el carácter degradante de las condiciones de trabajo, la hostilidad que conllevaban y, esencialmente, tenían por finalidad el resultado de atentar o poner en peligro la integridad personal del empleado. Esta concepción del acoso laboral surgida en la psicología coincide en su integridad con la protección que ofrece el Derecho laboral frente a este tipo de actos. Así, dentro del ordenamiento laboral, podemos encontrar definiciones de acoso laboral como la establecida en su día por el Instituto Nacional de Seguridad e Higiene en el Trabajo (INSHT), la cual describe el concepto mobbing como "aquella situación en la que una persona ejerce una violencia psicológica extrema, de forma sistemática y recurrente (como media una vez por semana) 
y durante un tiempo prolongado (como media unos seis meses) sobre otra persona o personas en el lugar de trabajo con la finalidad de destruir las redes de comunicación de la víctima o víctimas, destruir su reputación, perturbar el ejercicio de sus labores y/o lograr que finalmente esa persona o personas acaben abonando su lugar de trabajo". 6 En el mismo sentido, se pronunció el profesor de la Universidad de Alcalá, Iñaki Piñuel, identificando el término mobbing con las acciones de amenazar, criticar, ridiculizar, acechar, perseguir, acosar, cosificar o asediar a la persona trabajadora. ${ }^{7}$ Esta pluralidad de conductas encontrará protección y perfecta acogida dentro del Derecho laboral y, por ende, dentro del orden jurisdiccional social, por la vía de la vulneración de derechos de carácter fundamental de los trabajadores; ${ }^{8}$ con una aplicación mucho más extensiva que la prevista en el orden penal, como veremos a continuación.

También hemos hecho referencia con anterioridad a que el acoso laboral puede ser abordado desde el ámbito contencioso-administrativo. En concreto, la actuación de este orden jurisdiccional se circunscribe a enjuiciar la impugnación de las sanciones impuestas por la autoridad laboral a empresarios con motivo de realizar prácticas acosadoras que, de un modo u otro, atenten a la dignidad del trabajador; la revisión de sanciones impuestas a los funcionarios en el seno de procedimientos disciplinarios; o, por último, por la vía de la responsabilidad patrimonial o extracontractual.

Finalmente, el Tribunal Constitucional, dentro del especial y extraordinario orden jurisdiccional en el que opera, puede otorgar amparo, como así ha sucedido en numerosas ocasiones, por la vulneración de derechos fundamentales ante situaciones de acoso surgidas dentro del ámbito laboral; aunque reconociendo que no es a éste a quien le compete sentar un concepto jurisprudencial de acoso laboral, sino tan sólo valorar si ha existido o no vulneración de derechos constitucionales fundamentales. ${ }^{9}$

\section{UBICACIÓN DEL DELITO DE ACOSO MORAL LABORAL (MOBBING) EN EL CÓDIGO PENAL}

De lo expuesto con anterioridad, puede afirmarse con plena rotundidad que el acoso laboral es un problema social de carácter multidisciplinar que puede ser abordado desde la esfera de distintos ámbitos del Derecho y, en consecuencia, desde distintos órdenes jurisdiccionales. No obstante lo anterior, existen notables diferencias en la extensión atribuida al término "acoso laboral" entre unas ramas del Derecho y otras; mucho más amplia en el Derecho laboral que en, la contrapuesta y mucho más limitativa, aplicación que se prevé 
en el Derecho penal, lo cual dará lugar a que muchas conductas que sean sancionables por la vía de la jurisdicción social, no lo serán en la penal.

Para un correcto estudio de la figura penal del acoso moral laboral o mobbing, se considera de vital importancia que, antes de realizar cualquier tipo de análisis desde la perspectiva técnico-jurídica del delito, se ha de conocer con exactitud la concreta ubicación que el párrafo segundo del artículo 173.1 (lugar en el que se encuentra previsto el tipo penal) ocupa dentro de nuestro Código Penal; lo cual nos ayudará a alcanzar una mayor y mejor comprensión del fin que el legislador penal ha perseguido con su tipificación.

El delito de acoso moral laboral se encuentra previsto dentro del Libro II ("Delitos y sus penas"), Título VII ("De las torturas y otros delitos contra la integridad moral"), artículo 173.1, párrafo segundo, del Código Penal. ${ }^{10}$ Esta concreta ubicación del delito trae como principal consecuencia que el bien jurídico protegido en el mismo sea en exclusividad la "integridad moral" de la persona trabajadora.

La regulación del delito de acoso moral laboral se introdujo en el Código Penal a través de la reforma operada por la Ley Orgánica 5/2010, de 22 junio. ${ }^{11}$ Por medio de dicha inclusión, se reguló penalmente, por primera vez, un supuesto típico asimilado al trato degradante, aunque de menor gravedad que éste ("sin llegar a constituir un trato degradante"), pero sí teniendo que suponer un grave acoso para la víctima.

Con motivo de la específica ubicación dada al delito, puede afirmarse que, a pesar de que este tipo de conductas puedan constituir perturbaciones en el marco del desequilibrio de las relaciones de trabajo, el legislador ha perseguido distanciar la regulación del acoso laboral del contexto penal protector de los derechos de los trabajadores; ${ }^{12}$ previéndose, de este modo, un verdadero derecho del trabajador a la integridad moral en el desempeño de sus funciones. Lo que es lo mismo, es notoria la importancia que el legislador ha atribuido a la lesión del bien jurídico integridad moral en la previsión del delito de acoso surgido en las relaciones de trabajo.

Sin embargo, el verdadero sentido del tipo penal de acoso en el ámbito laboral privado o funcionarial puede extraerse de la Exposición de Motivos de la LO 5/2010, en la cual, haciéndose referencia a su tipificación, se establece lo siguiente: "Dentro de los delitos de torturas y contra la integridad moral, se incrimina la conducta de acoso laboral, entendiendo por tal el hostigamiento psicológico u hostil en el marco de cualquier actividad laboral o funcionarial que humille al que lo sufre, imponiendo situaciones de grave ofensa a la dignidad". 


\section{ELEMENTOS DEL TIPO PENAL DE ACOSO MORAL LABORAL (MOBBING). INTERPRETACIÓN JURISPRUDENCIAL}

El estudio de los elementos del tipo penal precisa de la diferenciación entre aquellos elementos que revistan un carácter objetivo (entendiendo por tales aquellos elementos puros de tipicidad, de los que se vale la ley penal para describir las conductas) y aquellos otros que dispongan de un carácter subjetivo (entendiéndose incluidos dentro de dicha categoría los elementos intelectuales y volitivos requeridos para su apreciación).

\subsection{ELEMENTOS OBJETIVOS}

A) Como primero de los elementos objetivos a destacar del delito, ha de significarse que la integridad moral de la persona trabajadora es el bien jurídico tutelado, como ya habíamos adelantado con anterioridad en reiteradas ocasiones; todo ello, producto de su localización en el Título VII ("De las torturas y otros delitos contra la integridad moral") del Código Penal. Del mismo modo, por ser específicamente la víctima un/a trabajador/a, conlleva que la protección de dicho bien jurídico tenga lugar de manera exclusiva tan sólo en el ámbito de la relación laboral (tanto de carácter privado como funcionarial).

El hecho de que sea la integridad moral de la persona trabajadora el bien jurídico protegido, constituye una de las características que dota de mayor singularidad al tipo penal de acoso moral en el trabajo, y va a ser, en la mayoría de supuestos, el factor determinante a la hora de valorar si concurre o no su debida aplicación. Es decir, resulta trascendental que sea éste el específico bien jurídico protegido, y no otro, pues, en el caso de lesión de otro bien jurídico diferente, aunque concurran el resto de elementos exigidos por el tipo penal, podremos estar ante la comisión de otra figura penal distinta, o bien ante unos hechos que carecen de relevancia penal, pero jamás condenables por la vía del artículo 173.1, párrafo $2^{\circ}$, del Código Penal. Este elemento de tipicidad dará lugar a que un gran número de situaciones calificables de acoso por otros órdenes jurisdiccionales sean atípicas en el ámbito penal.

En consecuencia, resulta esencial la determinación del concepto "integridad moral" otorgado por nuestra doctrina jurisprudencial, como bien jurídico protegido dentro del ámbito penal, que no debe de ser confundido con el derecho constitucional a la integridad moral (artículo 15 de la Constitución Española $^{13}$ ), distinto del anterior. ${ }^{14}$ A tal efecto, nuestro más alto tribunal de justicia ordinaria, el Tribunal Supremo, se pronunció en la Sentencia $325 / 2013,{ }^{15}$ en la cual establecía, respecto al bien jurídico penalmente 
protegido "integridad moral", lo siguiente: "La jurisprudencia de esta Sala ha venido señalando que la integridad moral se identifica con las nociones de dignidad e inviolabilidad de la persona, matizando que con el castigo de las conductas atentatorias a la integridad moral se pretende reafirmar la idea de que el ser humano es siempre fin en sí mismo, sin que quepa "cosificarlo", circunstancia que obliga a distinguir los simples ataques a la integridad física o psíquica de aquellos otros con repercusión directa en la dignidad humana".

Como bien es advertido por nuestro Tribunal Supremo, no deben ni pueden identificarse, como habitualmente ocurre, el bien jurídico a la integridad corporal o psíquica (o salud física o mental) con el bien jurídico a la integridad moral, ya que son realidades jurídicas completamente distintas y que se protegen de manera independiente, al menos en el ámbito del Derecho penal; siendo en este concreto matiz donde radica la gran diferencia entre la protección penal y la establecida en otras ramas del ordenamiento jurídico en cuanto al acoso laboral. En otros órdenes jurisdiccionales (como pueden ser, por ejemplo, el social y contencioso-administrativo) cabe estimarse una infracción por acoso laboral con motivo de una lesión psíquica o aniquilación mental al trabajador (lesión al bien jurídico salud mental o integridad psíquica), sin resultar necesaria la lesión a su integridad moral. Esto no es trasladable al ámbito penal, en el cual se diferencian plenamente ambas realidades jurídicas, teniendo además una notable importancia dicha distinción, ya que nos encontraremos ante una figura penal u otra. Es decir, aunque se trate de bienes jurídicos que con habitualidad se encuentran relacionados (normalmente, cuando se lesiona a uno de ellos, al otro también), no deben de ser confundidos entre sí. Por ello, si concurriese la comisión de ambos delitos, nos encontraremos ante un concurso de delitos, y no de normas o leyes.

Lo establecido en el párrafo precedente adquiere todavía mayor rotundidad si se observa lo preceptuado en el artículo 177 del Código Penal, el cual prevé el castigo por separado de los hechos que atenten, además de a la integridad moral, a otros bienes jurídicos diferenciados: vida, integridad física, salud (debe de entenderse incluida la mental), etcétera. Es decir, el propio precepto penal dispone, expresamente, la distinción e independencia de tales bienes jurídicos protegidos. ${ }^{16}$

B) Una vez determinado el bien jurídico protegido por el tipo penal, hemos de advertir igualmente que existe otra importante particularidad en cuanto al sujeto activo y pasivo del delito de acoso moral en el trabajo: se prevé con exclusividad una modalidad "vertical-descendente". El tipo penal exige, además de un ataque a la integridad moral del trabajador/a, la concurrencia de una prevalencia de la posición de superioridad que debe ostentar el sujeto 
activo-autor del delito, dentro de la relación laboral, respecto del sujeto pasivo (trabajador/a), este último subordinado a la referida posición de aquél. Es decir, por propia tipicidad del delito, ha de existir una relación de superioridad del sujeto activo respecto del sujeto pasivo, así como la prevalencia de dicha posición en la conducta acosadora desarrollada; todo ello, para que pueda ser apreciado el delito. Hemos de señalar, no obstante, que dicha posición de superioridad debe ser entendida en un sentido amplio, tanto desde el punto de vista jerárquico como desde el punto de vista funcional.

Por lo tanto, todos los supuestos de acoso entre trabajadores de igual posición (modalidad "horizontal" o "entre iguales"), así como los ocasionados por un trabajador que ostenta una posición de inferioridad respecto de su superior (modalidad "vertical-ascendente"), aun cumpliéndose de manera íntegra los restantes elementos del tipo penal, serán totalmente atípicos desde la óptica de este delito. Este elemento objetivo del tipo, en conjunción con el específico bien jurídico protegido, descartarán de por sí un gran número de conductas que puedan ser entendidas como verdaderas situaciones de acoso desde una perspectiva común, así como desde la perspectiva de otros ámbitos del ordenamiento jurídico.

C) Respecto a la conducta típica del delito, el precepto penal la define como "realizar actos hostiles o humillantes de forma reiterada que, sin llegar a constituir trato degradante, supongan grave acoso contra la víctima"; lo cual nos lleva a deducir que nos encontramos ante una conducta típica de carácter eminentemente valorativo, susceptible de plantear multitud de problemas a nivel interpretativo. En consecuencia, conviene analizar por separado los componentes que integran dicha conducta típica, observando de manera paralela la interpretación establecida por nuestra doctrina jurisprudencial, para conocer con exactitud la interpretación correcta que debe de darse al precepto penal.

a) En primer término, la conducta típica debe de consistir en la realización de actos hostiles o humillantes. Este requisito, per se, es de absoluta trascendencia para conocer si realmente nos encontramos ante una lesión al bien jurídico integridad moral o no. Es decir, la comisión de actos de tal carácter está plenamente relacionada con la lesión del bien jurídico protegido. De este modo, para que unos determinados actos puedan tener el carácter de atentatorios contra la integridad moral dentro del ámbito penal, se exige que éstos resulten especialmente vejatorios para la víctima (trabajador/a) que los sufre, en el sentido de que resulten humillantes o supongan una grave ofensa para su dignidad. Ésta será la fina línea divisoria que marcará la diferencia entre calificar, desde la perspectiva penal, unos hechos constitutivos 
de acoso como lesivos tan sólo de la salud mental de una persona, o bien como lesivos de la integridad moral, o incluso infractores de ambos bienes jurídicos (concurso de delitos). En numerosas ocasiones nos encontramos ante empresarios que ejercen una conducta de persecución mental plena hacia la persona trabajadora, catalogable incluso de "aniquilación mental o psíquica", a través de la cual persigue alcanzar un fin determinado (normalmente, conseguir que el trabajador claudique en sus esperanzas de continuar en la empresa, accediendo a marcharse "voluntariamente" de la empresa, ahorrando el empresario, de este modo, el pago de posibles indemnizaciones por despido). Pues bien, si esta conducta desarrollada por el empleador no tiene un carácter envilecedor o atenta contra la dignidad del trabajador, podrá serle castigado por atentar contra la salud mental del trabajador (delito de lesiones ${ }^{17}$ ), pero no por el delito de mobbing o acoso moral laboral, puesto que en el supuesto planteado no se atentaría contra el bien jurídico a la integridad moral, que es el específicamente protegido. ${ }^{18}$

A mayor abundamiento, podemos realizar una objeción más respecto a la acción típica del delito: realizar actos humillantes u hostiles. La expresión utilizada -realizar actos- presenta el siguiente interrogante: $i$ se exige por el tipo penal la realización de conductas activas, sin que pueda tener cabida su comisión a través de comportamientos omisivos? A cuya respuesta debemos de contestar en sentido negativo. Esto es, cabe también la realización del tipo penal a través de actos o comportamientos omisivos dirigidos hacia la víctima. Así, encontramos numerosos ejemplos jurisprudenciales en los que se condena a personas jerárquicamente superiores dentro de la relación laboral por el delito acoso moral laboral a consecuencia de ejercer un comportamiento completamente omiso, durante un largo período de tiempo, hacia la persona trabajadora de posición inferior, como si ésta no existiera; o incluso, por el hecho de no haber asignado tarea alguna a dicha persona trabajadora, dejándola sin función dentro del organigrama empresarial o funcionarial durante un largo período de tiempo. ${ }^{19}$

b) En segundo término, se exige la reiteración en la conducta desarrollada como elemento nuclear. Esta exigencia en la previsión del delito trata de dar respuesta, no a actos aislados o esporádicos (aunque revistan gravedad), sino a prácticas de maltrato con cierta estabilidad en el tiempo que se dirigen a provocar una situación humillante o de hostigamiento a la víctima. De este modo, se delimita, de nuevo, el campo de aplicación del tipo penal: el acoso no puede ser confundido con un episodio aislado, ni tampoco con varios actos inconexos temporalmente entre sí, aunque afecten al mismo trabajador. Se exigirá adoptar una perspectiva de conjunto o de conexión de los actos 
realizados contra la víctima, ya que se requiere que, con carácter global, todos ellos, "supongan grave acoso" a la persona trabajadora. Ello, implica la imposibilidad de evaluar el carácter o entidad de la conducta desde una perspectiva singular.

De igual modo, si la idoneidad para menoscabar la integridad moral del trabajador se infiere tan solo de un acto, aun teniendo como resultado efectos perniciosos para la víctima que se prolongan en el tiempo, tampoco podría aplicarse el tipo penal de acoso, ya que el comportamiento del sujeto activo debe de ejecutarse en una pluralidad de actos, como requiere el tipo (" $d e$ forma reiterada"). Así, no se integran los actos aislados que se olvidan y dejan de producir sus efectos negativos en la psique de quien los sufre, sino que el comportamiento acosador debe de mantenerse constante en el tiempo, generándose un ambiente irrespirable, que el autor del delito sostiene de forma deliberada mermando de manera constante la autoestima y resistencia moral de la víctima. ${ }^{20}$

De lo anterior, podemos concluir que nos encontramos ante una reiteración que exige algo más que la nota típica de habitualidad propia de otros delitos, como el de la violencia intrafamiliar, ${ }^{21}$ para el cual se exige normalmente un número de tres o más episodios de violencia. El sentido que tiene la reiteración en el tipo penal objeto de análisis es distinto, ya que cada uno de los actos, considerados individualmente, pueden ser no sólo no constitutivos de este delito sino incluso irrelevantes penalmente; de modo que es precisamente la reiteración y la conformación de una pauta de conducta lo que hace emerger la antijuridicidad del comportamiento.

c) En cuanto a la conducta típica se refiere, se exige la producción de un grave acoso contra la víctima, sin llegar a constituir trato degradante. En concreto, se exige que la concatenación de actos hostiles o humillantes realizados por quien se prevale de su relación de superioridad laboral "supongan un grave acoso" contra la víctima, sin llegar a constituir trato degradante. No obstante, el precepto penal no define dicho término ("grave acoso"), ni cómo ha de graduarse su alcance.

Atendiendo a la ubicación sistemática del delito en el Código Penal, situándose en el mismo número que regula el delito de trato degradante y bajo un similar marco punitivo, se puede concluir que este elemento de tipicidad constituye, implícitamente, el correlato del menoscabo grave de la integridad moral, aunque sin llegar a la intensidad de la comisión del delito de trato degradante. En definitiva, no hay que realizar especiales esfuerzos para deducir que el delito de trato degradante exige una mayor gravedad o entidad para su 
comisión que la del delito de acoso moral en el ámbito del trabajo; aunque también grave la conducta de este último.

Ahora bien, el punto clave reside en que, si este requisito de gravedad se pone de relieve junto al elemento de reiteración en el tiempo y de pluralidad de los actos, el cual no es exigido en la figura del trato degradante, serán todos estos aspectos los que marcarán la diferencia entre aplicar uno u otro delito. Es decir, el tipo penal del artículo 173.1, primer párrafo, puede ser cometido, o bien por medio de tan sólo un acto, si éste supera la suficiente gravedad que se exige, o bien por medio de una pluralidad de actos que revistan, singularmente considerados (uno por uno), la suficiente gravedad para su apreciación como trato degradante (en cuyo caso, habrá varios delitos de trato degradantes cometidos), aunque sean inconexos entre sí. Ahora bien, para la apreciación del delito de mobbing o acoso moral laboral se requiere que exista una pluralidad de actos (no cabe la condena por la realización de un único acto atentatorio contra la integridad moral); debe de existir una continuidad temporal o reiteración en la conducta, con conexión entre todos los actos realizados; y se precisa de una gravedad (aunque inferior a la del trato degradante) en esa continuidad o pluralidad de actos considerados en su conjunto (no individualmente, como ocurre en el delito de trato degradante). Todas estas diferencias existentes entre un delito y otro serán las que marcarán la línea de diferenciación entre apreciar un tipo penal u otro. Lo que es lo mismo, serán estos criterios diferenciadores los que permitirán resolver un posible concurso de normas o leyes entre ambas figuras penales. ${ }^{22}$

d) Por otro lado, el hecho de que el tipo penal exija expresamente la producción de un grave acoso a la víctima nos da a entender que éste, en un principio, y conforme a la redacción del propio precepto penal, es un delito de resultado. Ahora bien, a efectos de consumación del delito, nuestra jurisprudencia ha sostenido que basta con que la conducta desarrollada entrañe un riesgo relevante suficiente para que la lesión pueda producirse, en el sentido de que tan sólo con que la conducta desarrollada sea considerada como idónea ex ante para producir la lesión a la integridad moral, será suficiente para entender consumado el delito. ${ }^{23}$

D) Por último, fuera de la conducta típica analizada, otro aspecto a destacar del delito es que éste exige que la lesión a la integridad moral de la víctima debe de ser imputable a la reiteración de los actos hostiles o humillantes que hayan sido realizados por el sujeto activo; es decir, ha de existir relación de causalidad entre la conducta desarrollada y el resultado acosador producido. No podrá ser apreciado el tipo penal en aquellos casos en los que se hayan desarrollado actos vulneradores de la integridad moral de la persona trabajadora si, producido el 
resultado lesionador, se demuestra que ese daño se ha debido a otro motivo o por el ataque de persona distinta (algo altamente difícil de probar).

\subsection{ELEMENTOS SUBJETIVOS}

En lo concerniente al elemento subjetivo del tipo penal, se requiere de manera imprescindible un comportamiento doloso, debiendo de abarcar no solo la consciencia respecto a los actos llevados a cabo, sino también sobre la incidencia e impacto de los mismos en la integridad moral de la víctima, y que el infractor actúe conforme a esa voluntad.

No obstante, se llega a admitir para la apreciación del tipo penal la posibilidad del dolo directo de segundo grado o de consecuencias necesarias (el autor acepta como seguro la producción de un resultado que no pretende pero que se constituye como necesario para el que realmente pretende); por ejemplo, como ocurre en el caso del empresario que pretende conseguir que un trabajador abandone voluntariamente el trabajo, aunque es consciente de que para ello tenga que lesionar su integridad moral. Asimismo, se admite la posibilidad del dolo indirecto o eventual (el autor ve como posible la producción de un resultado lesivo, que no pretende, pero aun así decide hacerlo); diferenciándose del anterior en que en este caso se prevé como posible el resultado que no pretende conseguir y, en cambio, en el dolo directo de segundo grado, se tendría la certeza de que ese resultado no deseado se produciría.

En un principio, no se admiten las formas imprudentes de ejecución en este delito, dada la falta de admisión expresa por el tipo penal, en aplicación del artículo 12 del CP. ${ }^{24}$

$\mathrm{Al}$ respecto, resulta altamente ilustrativa la tan reiterada SAP de Madrid $18 / 2019,{ }^{25}$ la cual, a través de una comparativa con el delito de hurto, ejemplifica muy bien las posibilidades de dolo aceptadas para la comisión del delito: “(...) sin duda describen una conducta exclusivamente atribuible a la actitud intencionada del acusado que incorpora el elemento subjetivo del dolo admisible también a título eventual, tal y como se expone en la propia sentencia; inclusive puede decirse que podríamos estar ante un dolo de consecuencias necesarias, no se requiere un dolo específico o elemento intencional que vaya más allá de conocer que la conducta objetivamente afecta a la integridad moral, y consentir con ello. Ese dolo puede aparecer repentinamente; es compatible con un estado de ira; no exige una reflexión deliberativa seguida de una decisión meditada y asumida fríamente; la incidencia en el sentimiento de dignidad de la víctima fluye de la situación y 
el marco que son conocidos por el acusado en todos sus detalles (...) No es necesaria una motivación distinta a la propia descripción del hecho probado en secuencia querida por el acusado siendo muy pertinente la aplicación al caso del aforismo latino: res ipsa loquitur, de manera que exigir una prueba específica de una intencionalidad o una motivación ad hoc para justificar la concurrencia del ánimo tendencial en estos delitos, sería, mutatis mutandi, como reprobar una sentencia condenatoria por delito de hurto por limitarse a decir que el acusado se apoderó de la cartera de un tercero sin expresar qué pruebas abonan la presencia de un ánimo de lucro, ni motivar de forma específica por qué se ha deducido ese ánimo de lucro; por tanto, el elemento subjetivo se infiere sin más de la propia secuencia objetiva del hecho".

\section{CONCLUSIONES}

Del conjunto de argumentaciones aducidas a lo largo del presente estudio, se pude extraer una conclusión que resulta inequívoca: el tipo penal de mobbing no prevé un delito de acoso genérico en el ámbito del trabajo, sino únicamente de aquellas conductas acosadoras que atenten contra la integridad moral de la persona trabajadora, entre otras muchas exigencias.

El fin verdadero que hemos perseguido mediante este trabajo, no es otro que el de ilustrar al lector de las tan extraordinarias limitaciones que presenta la regulación del tipo penal, con la correspondiente acotación de su ámbito protector; lo cual no deja de ser producto del tan vigorado principio de tipicidad penal.

Por todo ello, y a modo de autocrítica, entendemos que el legislador penal ha emprendido una tendencia excesivamente limitativa en la tipificación del delito. La sociedad en la que vivimos nos demuestra día a día, cada vez con más frecuencia, que el acoso que sufren numerosos trabajadores consiste con habitualidad en un desgaste y una merma mental en su persona; mucho más frecuente que la lesión a la integridad moral. El hecho de que el tipo penal se encuentre limitado en exclusiva a la protección a la integridad moral da lugar a que la mayoría de tales conductas sean impunes por no reunir el requisito de tipicidad de lesión al bien jurídico concreto. Sabemos que existe la posibilidad del castigo por la vía del delito de lesiones a la salud mental, ${ }^{26}$ pero no olvidemos que para su apreciación se requiere un animus laedendi en el autor de los hechos, aspecto que no concurre con mucha frecuencia en el sujeto activo del mobbing. Dicho con otras palabras, una conducta acosadora no vulneradora de la integridad moral podría dar lugar a la impunidad desde la perspectiva de ambos delitos. 
De igual modo, entendemos que el legislador penal incurre en un craso error de tipificación al no haber incluido dentro del ámbito de aplicación del delito la posibilidad de reprochar penalmente el acoso surgido entre trabajadores que ostentan una posición de igualdad de rango dentro de la esfera laboral, e incluso el acoso cometido por un inferior hacia su superior, también posible. Conductas atípicas que, de la misma manera, repercuten en la limitación del ámbito de aplicación del delito.

El Derecho penal debe ser una rama del ordenamiento jurídico con una capacidad extraordinaria de adaptación a las circunstancias cambiantes de nuestra sociedad; deber con el que, bajo nuestro humilde criterio, no se ha cumplido. Si el acoso en el trabajo es un problema social que se muestra en incremento, que generalmente provoca lesiones en la psique de quien lo padece, más que en la integridad moral, así como habitualmente sucede entre iguales e incluso posiblemente de un inferior a un superior en la relación laboral, consideramos que es necesaria una modificación del tipo penal que corrija todo este tipo de deficiencias. A día de hoy, insistimos, son latentes las muestras que evidencian su limitado funcionamiento. Por encima de todo, este autor lo que espera y desea es haber ilustrado satisfactoriamente sobre la materia al lector.

\section{BIBLIOGRAFÍA}

ESCARTÍN, J., RODRÍGUEZ-CARBALLEIRA, A. y ZAPF, D. (2012), Guías de intervención. Mobbing. Acoso psicológico en el trabajo, Síntesis, Madrid.

LAFONT NICUESA, L. (2008), El delito de acoso moral en el trabajo, Tirant lo Blanch, Valencia.

MIR PUIG, C. (2010), "El mobbing o acoso moral o psicológico en el trabajo", LUZÓN PEÑA, D. M. (Dir.), Libro Homenaje a Santiago Mir Puig.

OTERO GONZÁLEZ, P. y POMARES CINTAS, E. (2010), Acoso laboral (mobbing), Comentarios al Comentarios a la Reforma penal de 2010, Tirant lo Blanch, Valencia.

PIÑUEL Y ZABALA, I. (2006), "El Mobbing o acoso psicológico en el Trabajo, en el curso multidisciplinar del CGPJ: El mobbing desde la perspectiva social, penal y administrativa", Estudios de Derecho Judicial, $\mathrm{n}^{\circ}$ 94, pp. 15-82.

RIVAS VALLEJO, P. y GARCÍA VALVERDE, M. D. (2015), Tratamiento integral del acoso, Aranzadi, Pamplona. 
RODRIGUEZ SANTANA, F. A. (2004), "El acoso moral en el trabajo", Revista de Ciencias Jurídicas, $\mathrm{n}^{\mathrm{o}}$ 8-9.

ROMERO RÓDENAS, M. J. (2005), Protección frente el acoso moral en el trabajo, Bormazo, Albacete.

SERRANO GÓMEZ, A. y SERRANO MAÍlLO, A. (2017), Curso de Derecho Penal Parte Especial, Dikynson, Madrid.

VILLEGAS FERNÁNDEZ, J. (2007), "Presente y futuro del delito de acoso laboral (Comentario a la sentencia de 27 de septiembre del año 2006 del juzgado de lo penal número uno de Jaén)", Actualidad Jurídica Aranzadi, $\mathrm{n}^{\mathrm{o}} 731$.

NOTAS

1 Abogado ejerciente, colegiado $n^{\circ} 4403$, perteneciente al Ilustre Colegio Provincial de Abogados de Jaén. Doctorando en el Programa de Doctorado en Derecho de la Universidad de Jaén. Correo electrónico: antoniomc@martinez-asociados.es.

2 Artículo 173.1, párrafo $2^{\circ}$, de la Ley Orgánica 10/1995, de 23 de noviembre, del Código Penal. Boletín Oficial del Estado, 24 de noviembre del 1995, núm. 281, pp. 33987 a 34058 (CP, en adelante).

3 Artículo 172 ter del CP.

4 Artículo 184 del CP.

5 SÁNCHEZ, J. (2019), "En 2019, crece el acoso laboral en España”, Pymes y autónomos, Madrid, https://www.pymesyautonomos.com [consultado el 10 de octubre del 2020].

6 MARTÍN-DAZA, F., PÉREZ BILBAO, J. y LÓPEZ GARCÍA-SILVA, J. A. (1998), El hostigamiento psicológico en el trabajo: mobbing, Instituto Nacional de Seguridad e Higiene en el Trabajo, Ministerio de Trabajo y Asuntos Sociales de España.

7 PIÑUEL, I. (2001), Mobbing. Cómo sobrevivir al acoso psicológico en el trabajo, Sal terrae, Santander.

8 CAPÍTULO XI: De la tutela de los derechos fundamentales y libertades públicas, TÍTULO II: De las modalidades procesales, LIBRO SEGUNDO: Del proceso ordinario y de las modalidades procesales, de la Ley 36/2011, de 10 de octubre, reguladora de la jurisdicción social. Boletín Oficial del Estado, de 11 de octubre del 2011, núm. 245, pp. 106584 a 106725 (LRJS, en adelante).

9 Sentencia 56/2019 del Tribunal Constitucional, Sala Primera, de 6 de mayo del 2019 (Recurso $n^{\circ}$ 901/2018). Extraída en https://laleydigital.laleynext.es [consulta el 23 de agosto del 2020]. Esta Sentencia constituye un verdadero ejemplo de cómo lo que puede resultar un atentado contra la integridad moral en la vía constitucional, puede no serlo en la vía penal. En dicha Sentencia, el Tribunal Constitucional aprecia una vulneración al derecho a la integridad moral (artículo 15 de la Constitución Española), por la vía de la falta de proporcionalidad de la medida adoptada (arrancar pelos de las axilas), aun faltando el elemento intencional de vejar o humillar a la persona (requisito imprescindible para la apreciación del delito mobbing en el ámbito penal).

10 El párrafo $1^{\circ}$ (referido al delito de trato degradante), el cual igualmente reseñamos por hacer remisión al mismo el párrafo $2^{\circ}$ (tipo penal del mobbing) en cuanto al tratamiento punitivo, $\mathrm{y}$ el párrafo $2^{\circ}$ del apartado $1 \mathrm{del}$ artículo $173 \mathrm{del} \mathrm{CP}$, establecen con literalidad lo siguiente: “ 1 . El que infligiera a otra persona un trato degradante, menoscabando gravemente su integridad moral, será castigado con la pena de prisión de seis meses a dos años.Con la misma pena serán castigados los que, en el ámbito de cualquier relación laboral o funcionarial y prevaliéndose de su relación de superioridad, realicen contra otro de forma reiterada actos hostiles o humillantes que, sin llegar a constituir trato degradante, supongan grave acoso contra la víctima". 
11 Ley Orgánica 5/2010, de 22 de junio, por la que se modifica la Ley Orgánica 10/1995, de 23 de noviembre, del Código Penal. Boletín Oficial del Estado, 23 de junio de 2010, núm. 152, páginas 54811 a 54883 (LO 5/2010, en adelante).

12 Título XV del CP.

13 Constitución Española. Boletín Oficial del Estado, de 29 de diciembre de 1978, núm. 311, pp. 29313 a 29424 (CE, en adelante).

14 En este sentido, la Sentencia 56/2019 del Tribunal Constitucional, citada con anterioridad.

15 Sentencia 325/2013 del Tribunal Supremo (Sala Segunda, de lo Penal), de 2 abril de 2013 (Rec. 1148/2012). Extraída de http://www.laleydigital.laleynext.es [consultada el 30 de marzo del 2021].

16 En este sentido, se pronuncian una multitud de resoluciones judiciales, de entre las cuales podemos destacar, por la riqueza que entraña su texto en la materia, la Sentencia 18/2019 de la Audiencia Provincial de Madrid (Sección 7 ), de 16 de enero de 2019 (Recurso n ${ }^{\circ}$ 1101/2017). Extraída de http://www.laleydigital.laleynext.es/ [consultada el 20 de marzo del 2021]. De igual forma, la Sentencia 542/2018 de la Audiencia Provincial de Barcelona (Sección 2a ), de 3 de septiembre de 2018 (Recurso $\mathrm{n}^{\circ}$ 112/2017), citando al efecto múltiple doctrina constitucional y jurisprudencia emanada del Tribunal Supremo. Extraída de http://www.laleydigital.laleyne xt.es/ [consultada el 20 de marzo del 2021]. Ahora bien, se ha de resaltar, especialmente, el Auto 67/2009 de la Audiencia Provincial de Madrid (Sección 5 $5^{\text {a }}$, de 12 de enero de 2009 (Recurso $n^{\circ} 662 / 2008$ ), el cual señala las distinciones entre los distintos órdenes jurisdiccionales, indicadas en las líneas que preceden, así como la finalidad que persiguen los tipos penales que se encuentran previstos dentro del Título VII del Código Penal, cuya protección va referida a la integridad moral de las personas. Extraída de http://www.laleydigital.laleynext.es/ [consultada el 20 de marzo del 2021].

17 Ex artículo 147 del CP.

18 De manera muy oportuna, sobre este aspecto, ha de traerse a colación la Exposición de Motivos, transcrita anteriormente, de la LO 5/2010, en la cual se expresa que, para que pueda apreciarse una situación de acoso en el ámbito del trabajo, dichos actos de hostigamiento deben revestir un carácter humillante, suponiendo una grave ofensa para la dignidad de la persona trabajadora.

19 En vía penal, pueden mencionarse, a modo ejemplificativo, las siguientes: Sentencia 18/2018 de la Audiencia Provincial de Cáceres (Sección 2a), de 9 de enero de 2018 (Recurso n ${ }^{\circ}$ 1036/2017); así como la Sentencia 945/2010 del Tribunal Supremo (Sala Segunda, de lo Penal), de 28 de octubre de 2010 (Recurso n ${ }^{\circ}$ 701/2010). Extraídas ambas de http://www.laleydigital.laleynext .es/ [consultadas el 14 de febrero del 2021].

20 En este sentido, encontramos la Sentencia 206/2011 de la Audiencia Provincial de Zaragoza (Sección 6 $6^{\text {a) }}$, de 1 de junio de 2011 (Recurso no 84/2011). Extraída de http://www.laleydigital .laleynext.es/ [consultada el 15 de marzo del 2021].

21 Artículo 173.2 del CP.

22 En apoyo a tales argumentos, puede volver a citarse la Sentencia 18/2019 de la Audiencia Provincial de Madrid. Asimismo, la Sentencia 694/2018 del Tribunal Supremo (Sala Segunda, de lo Penal), de 21 de diciembre de 2018 (Recurso n 2486/2017). Extraída de http://www.lale ydigital.laleynext.es [consultada el 20 de marzo del 2021].

23 Entre otras, la Sentencia 220/2005 del Tribunal Constitucional (Sala Primera), de 12 de septiembre de 2005 (Recurso $\mathrm{n}^{\circ}$ 1221/2002). Extraída de http://www.laleydigital.laleynext.es [consultada el 28 de septiembre del 2020].

24 Artículo 12 del CP: "Las acciones u omisiones imprudentes sólo se castigarán cuando expresamente lo disponga la Ley".

25 Hace referencia la tan reiterada Sentencia 18/2019 de la Audiencia Provincial de Madrid.

26 Artículo 147 del CP. 